\title{
EDUCAÇÃO GEOGRÁFICA, DOCÊNCIA E O CONTEXTO DA PANDEMIA COVID-19
}

\section{Geographical education, teaching and the context of COVID-19 pandemic \\ Educación geográfica, enseñanza y el contexto de pandemic COVID-19}

\author{
Manoel Martins de Santana Filho \\ Coordenador do Programa de Pós-graduação em Geografia - PPGGEO-FFP \\ manoel.santana@gmail.com
}

Artigo enviados para publicação em 24/04/2020 e aceito em 28/04/2020

DOI: $10.12957 /$ tamoios.2020.50449

\begin{abstract}
Resumo
O texto apresenta uma discussão sobre a docência e o ensino de geografia no contexto da COVID-19, problematiza as condições do trabalho docente e aponta temáticas para uma educação geográfica contemporânea e pertinente ao tempo de pandemia, considerando as orientações para a ação dos professores segundo as gestões de secretaria de educação. Os elementos norteadores do ponto de vista objetivo se baseiam no contexto das redes públicas e privadas da região metropolitana do Rio de Janeiro, principalmente.
\end{abstract}

Palavras-chave: educação escolar, prática docente, educação geográfica, covid-19.

\begin{abstract}
The article present a discussion on teaching practice and Geography education in the context of COVID-19, complexifies the conditions of teaching labor and displays relevant and contemporary thematics for geographic education in pandemic times, taking into account the orientations that were given to the teachers by the management of Education Bureaus. On the objective point of view, the guiding elements are mainly the context of both public and private schools of the metropolitan region of Rio de Janeiro.
\end{abstract}

Key words: school education, teaching practice, geographic education, covid-19.

\section{Resumen}

El texto presenta una discusión sobre el trabajo docente y la enseñanza de la geografía en el contexto de COVID-19, problematiza las condiciones del trabajo de enseñanza y señala temas para la educación geográfica contemporánea relevantes para el momento de la pandemia, considerando las pautas para la acción de los maestros de acuerdo con la secretaría de educación. Los elementos rectores desde el punto de vista objetivo se basan principalmente en el contexto de las redes públicas y privadas en la región metropolitana de Río de Janeiro.

Palabras clave: educación escolar, práctica docente, educación geográfica, covid-19. 


\section{O fato, os eventos, as ações}

O cenário da pandemia que assola o mundo desde o primeiro trimestre de 2020 pelo agente patogênico corona vírus, denominado COVID-19, alterou profundamente e de múltiplas maneiras a vida cotidiana, o mundo produtivo, o sistema financeiro global, as possibilidades de circulação de pessoas, produtos, serviços e informação. O impacto real desse contexto será motivo de muitos estudos e levaremos um razoável tempo para compreender tantas consequências derivadas das condições atuais de existência humana neste ano. E no futuro.

Não é difícil entender a relação do medo da doença com a produção das geografias humanas, como bem nos ensinou Tuan (2005, p. 139-140):

\footnotetext{
"Somos a favor da vida, especialmente como se manifesta na saúde de nosso próprio corpo. A integridade do corpo é o alicerce de nossa sensação de ordem e completude. Quando adoecemos, também parece que o mesmo acontece com o mundo. Quando fechamos os olhos e morremos, o mundo também cai no esquecimento. O corpo é nosso cosmo mais íntimo, um sistema cuja harmonia é sentida em vez de percebida simplesmente."
}

Muitos elementos desse cenário apontam para a dinâmica global do mundo, revelando a globalização da vida inteira, no modo do viver humano que povos inteiros reproduzem. Os processos produtivos diversos, a circulação das pessoas, o ritmo frenético das trocas econômicas, tudo isso parou sob o freio da morte ali na esquina, no porto, nas estações rodoferroviárias, nos aeroportos: a contaminação iminente e a autopreservação alertam para a finitude dos seres humanos na superfície do planeta. A atividade educacional é inegavelmente atingida, limitada pelo isolamento físico domiciliar, com impacto direto e crucial na vida das famílias, das escolas públicas e privadas, nos processos de aprendizagem e na docência. Como esse impacto afeta de modo mais ou menos intenso pessoas e grupos humanos? Como a profissionalidade docente, surpreendida, é chamada a responder, atuar e mudar a partir de então?

Temos lido muitos estudiosos apontarem cenários possíveis para o futuro da humanidade. São leituras ainda prematuras, interpretações realizadas no calor dos fatos e emoções. De maneira geral são esforços legítimos, a partir dos quais cientistas de diferentes áreas aplicam conhecimentos e critérios objetivos para compreender fatos e processos acelerados em curso. Negacionistas, ao contrário, entregam uma massa de informações enunciadas em preconceitos, crenças particulares e até superstições. Tudo 
isso agravado pela aberração das Fake News! Nessa miríade de possibilidades, nosso foco de interesse na educação escolar e na geografia é o fio conduto das ideias centrais desse texto.

A docência e a educação escolar estão abaladas. A pandemia, ao nos isolar uns dos outros, estudantes, professores, pedagogos, gestores públicos e privados, abala a dinâmica da escola: seu sentido baseado na convivência e compartilhamento de ideias e saberes, na transmissão de conteúdos consolidados e conduzida por práticas seculares encontra-se revirado. Que fazer?

De alguma maneira é possível reconhecer que grandes eventos históricos e processos de grandes transformações já provocaram mudanças em relação à educação no mundo ocidental. Da sociedade greco-romana até as diversas Revoluções Industriais a educação sempre ocupou um lugar emancipatório para aqueles que a alcançam, mas ao mesmo tempo, sempre retratou também as desigualdades humanas que os sujeitos históricos podem produzir e ter quanto à sua compreensão do meio, das práticas culturais e de si mesmo. Pensada e conduzida por e para poucos, depois ampliada para outras camadas de população para que pudessem se reproduzir como força de trabalho, a educação sempre foi foco dos poderosos. Tanto serviu para produzir status quo quanto para instalar forças questionadoras e revolucionárias, elitizada ou popularizada, os processos educacionais estão sempre disputados por narrativas e interesses diversos, invariavelmente dominantes, elitizados. No caso brasileiro, como de tantos outros países do mundo que viveram processos de dominação colonial, a escola se desenvolveu numa mistura dos poderes políticos, religiosos e econômicos. O momento atual nos aponta várias faces dessas desigualdades, interesses e perversidades educacionais. E mais do que isso, desnuda a feiura de um passado colonial escravagistas. A pandemia explicita e despeja, no cotidiano, inúmeras desigualdades dessa herança que conformou a escola e os professores brasileiros.

Os processos educacionais, a aprendizagem derivada exclusivamente do cumprimento de um currículo é um tema que, nos parece, não está ainda no foco de uma discussão fecunda nesses meses iniciais de 2020. A urgência de fazer funcionar a escola, de manter a intervenção pedagógica orientada por conteúdos e instrumentos de memorização e controle vem prevalecendo, tanto nas ações dos gestores da educação pública quanto nas empresas educacionais. Vale destacar o encantamento apressado com os aparatos tecnológicos, com a mediação por meio das redes virtuais. Nada disso é promissor o suficiente numa perspectiva emancipatória, pois a tendência que deriva dela 
é ainda mais desigualdade, mais fragilidade na profissão docente, mais desestruturação da educação pública. Em dadas situações, até de pouco zelo com a coisa pública, por exemplo, autorizar o uso de ferramentas digitais de empresas privadas sem contrato, por exemplo.

A urgência para que já nas primeiras semanas os professores, agora assumido tarefas a partir de suas casas, realizassem a transposição de seus planejamentos para plataformas virtuais e recursos pela internet conduz à reprodução pura e simples da exposição oral presencial para a repetição à distância das explicações e exercícios. É um arremedo de proposta pedagógica. Na prática, fere a docência na figura do professor e da professora que, não dominando devidamente aparatos de tecnologia, são conduzidos a trabalhar mais horas improvisando apresentações de slides para plataformas virtuais abertas; a expor sua prática e suas atividades em um ambiente totalmente novo, suas fragilidades documentadas, suas potencialidades negadas e interditadas por decisões de gabinete. Também é arremedo porque a prática educacional à distância, mesmo para seus defensores, exige que se repense a concepção de aprendizagem, da ação pedagógica, do currículo e dos próprios sujeitos do processo e não se constrói assim, de improviso. Há desigualdades explícitas também nesse aspecto.

O cenário desigual expõe uma contradição no modelo de ação seguida de maneira comum em diferentes redes de educação básica, sejam as redes públicas (federais, estaduais e municipais) seja na rede privada. Há secretários que apelam para a realização de atividades remotas, outros tentam impor a manutenção de um calendário com aulas a distância e uso de tv, e há aqueles que recomendam as atividades virtuais de modo complementar enquanto esperam a regularização ou validação posterior de tais atividades - a depender de pareceres dos conselhos estaduais ou nacional de educação ${ }^{1}$. Contudo, a realidade das escolas nas diferentes é muito distinta e desigual.

As escolas federais em geral possuem melhor infraestrutura e um quadro profissional com plano de carreira, uma qualificação mais consolidada e, por isso mesmo, costumam ter os próprios projetos pedagógicos e resistir com alguma firmeza aos desmandos comuns do atual Ministério da Educação. As redes estaduais são bastante diversificadas e apresentam muitas diferenças internas. Elas têm em comum que em suas escolas estão as comunidades mais vulneráveis, famílias trabalhadoras com grande dificuldade de dar suporte às atividades educacionais dos filhos, sem falar na penúria material e de infraestrutura nas unidades educacionais. No caso do Rio de Janeiro, por exemplo, a rede estadual possui escolas mais bem equipadas em dois casos: aquelas 
unidades históricas, em regiões centrais da capital fluminense ou da região metropolitana; ou as unidades nas quais a Secretaria Estadual de Educação (SEEDUC) implantou parcerias com empresas e consulados. Na periferia metropolitana e em cidades do interior o cenário é bem mais adverso. Como são adversas, em geral, as condições de vida e trabalho das comunidades onde estão instaladas e que compõem a clientela dessas escolas - aspecto bem referenciado pelo Censo Escolar e utilizado para corroborar ações do Ministério Público do Estado do Rio de Janeiro - MPRJ em seus documentos.

\section{Um pouco do Rio de Janeiro: atitudes recentes na gestão educacional do estado}

No Estado do Rio de Janeiro tem-se um quadro um tanto curioso. O secretário estadual de educação faz declarações em lives por redes sociais, porém, faltam instrumentos normativos claros. Tanto que o Ministério Público do Estado do Rio do Janeiro (MPRJ) passou a estabelecer prazos para que a pasta prestasse esclarecimentos, dado que "a SEEDUC não tornou público o plano de ação pedagógica referido pela Deliberação CEE n. 376, de 23 de março de 2020" (MPRJ, 2020)ํ․ Na compreensão do Secretário de Educação, a maneira de cumprir a carga horária curricular é por meio de educação à distância, situação também questionada pelo Ministério Público. Aliás, o documento do $\mathrm{MPRJ}^{3}$ está embasado em sólido conjunto de dados e informações. Diferente da condução de um sistema complexo de educação como o do Rio de Janeiro por meio de postagens nas redes sociais.

A política de anos recentes, no caso do Rio de Janeiro, de distribuição de computadores ainda está longe de permitir o atendimento de acesso à rede mundial, agravada pela infraestrutura insuficiente para o uso frequente de internet em sala de aula. Acompanhando estágios supervisionados em nosso trabalho na universidade é comum encontrar professores que compartilham seus planos de dados do próprio celular com os estudantes para que, eventualmente, possam realizar alguma atividade dessa natureza. $\mathrm{O}$ amplo, mas ainda não universal, uso de celulares pelos jovens estudantes não significa acesso e disponibilidade permanente para uso da rede e realização de atividades online (Vide dados do MPRJ, 2020, pág. 9). Em relatos recentes encontramos informações de famílias apelando parentes vizinhos no acesso à internet para que atividades, testes e material de envio obrigatório pelos estudantes pudessem ocorrer.

O cenário deixa de ser desigual e se torna abissal quando se considera o contexto das escolas da rede privada de ensino. Encontramos nele as escolas bilíngues, com 
mensalidades acima de muitos salários mínimos já na educação básica, nas quais há infraestrutura e projeto educacional com uso amplo de tecnologia, robótica etc. Ao contrário, temos as pequenas escolas privadas, tanto aquelas dos bairros tradicionais até os mais periféricos na região metropolitana. Respectivamente, no primeiro caso são escolas que atendem a um público de bom poder aquisitivo e famílias que podem dar suporte aos seus filhos, na segunda estão aqueles estudantes cujas famílias se desdobram e se endividam para manter os filhos de classe média e baixa longe das escolas públicas. Nas primeiras é mais comum que professores tenham salários e condições de trabalho razoáveis, já nas demais nem sempre se paga sequer o valor mínimo da hora aula acordado com os sindicatos. Em ambas pode ocorrer a superexploração do trabalho docente, mas por caminhos e estratégias diferentes. Nesse cenário da pandemia, o isolamento social põe em xeque a capacidade dessas escolas entregarem o produto educacional contratado, as aulas e as certificações, daí os mecanismos de pressão sob os educadores. Em ambas, as condições desiguais de acesso à internet e aparatos tecnológicos que as famílias da rede privada também vivem.

São geografias distintas vivenciadas por prática espaciais próprias e tratadas de modo uniforme por decisões da gestão educacional. A análise completa desses pareceres e a compreensão das forças em movimento nesse momento demandará muito investimento nas pesquisas futuras.

Por fim, conforme ressaltado em documentação do MPRJ motivado por questionamento do Sindicato Estadual dos Profissionais da Educação - SEPE:

"É fato notório que o público-alvo das escolas públicas é composto, majoritariamente, por adolescentes e jovens de baixa renda e em situação de vulnerabilidade social. Para além da notoriedade de tal quadro, inclusive para os fins do art. 374, I, do CPC, tal circunstância é demonstrada por diversos estudos e pesquisas amplamente reconhecidos pelos especialistas em educação.

Por exemplo, de acordo com a OCDE (Organização para a Cooperação e Desenvolvimento Econômico), 1 os estudantes brasileiros de 15 e16 anos de alto nível socioeconômico estão quase 3 anos de aprendizagem em Leitura à frente daqueles de nível socioeconômico baixo, da mesma idade. Tais dados são do Programme for International Student Assessment (Pisa 2018), da OCDE, e demonstram que a desigualdade entre alunos ricos e pobres no Brasil está entre as maiores do mundo”. (MPRJ, 2020, pág. 11)

O que se depreende desse cenário? Alguns elementos indicam que muitas decisões para a manutenção de atividades remotas vêm ocorrendo e promovendo algumas situações pouco confortáveis, para dizer o mínimo: 
a) A transferência de responsabilidade dos gestores para os professores quanto ao cumprimento ou não dos dias letivos;

b) Decisões nebulosas do ponto de vista legal e administrativo, faltando o devido e esclarecido respaldo na legislação vigente;

c) $\mathrm{O}$ modo apressado e superficial na condução das propostas de atividade remota gera nos professores um sentimento de impotência e fragilidade, quando não de exposição ao assédio e ameaças - para a rede pública relacionadas aos mecanismos administrativos e nas redes privada, o próprio emprego, a própria existência.

d) Um processo educacional totalmente focado no cumprimento de contéudos e na realização de exercícios e atividades, bem distante das narrativas e compreensões recentes oriundas de pesquisas educacionais, qual seja - a educação como direito humano; os processos formativos mais amplos que as atividades copiadas ou a sua reprodução pura e simples; a avaliação como processo.

e) A angústia que afeta as famílias que, agora isoladas em casa, precisam transformar suas salas, quando não o único cômodo comum de uma residência, no local do acontecimento da escola e suas atividades. Mais ainda, precisam ser os professores locais dos próprios filhos.

f) Nota-se também certo ar de acusação contra os educadores responsabilizados e culpados por não saberem transformar e produzir, com a devida urgência as atividades online, no mesmo padrão das aulas presenciais.

g) Uma autocobrança em uma parcela considerável dos professores - ciosos de suas responsabilidades, desdobram-se para não "abandonar os estudantes e dar o suporte que eles merecem em suas carências e necessidades educativas". Nesse caso, o preço dessa situação recai apenas sobre seus recursos e condições de remediar o que podem oferecer.

h) $\mathrm{O}$ descaso para as condições reais que a classe docente passa a viver na realidade de suas casas - transformar um cômodo da casa, se houver, ou uma mesa improvisada em local de trabalho remoto. Isto sem deixar de cuidar de filhos, dos idosos e manter dupla atenção às atividades escolares - suas e de seus filhos. Um quadro muito mais dramático para as mulheres!

Relatos diversos, encontrados nas redes sociais, apontam que a mobilização docente para alcançar o que é requisitado pelos órgãos de gestão pedagógica das escolas 
$\overline{\text { acontece sob muito improviso e muita tensão. A transmutação do planejamento original }}$ para atividades remotas atende a um imediatismo que parece desconsiderar a crise sanitária de fato. O objetivo primordial é manter o ativismo didático - seja sob a alegação do cumprimento dos dias letivos previstos, seja para permanecer entregando um serviço vendido nas escolas privadas. Gestores e famílias pouco têm sido orientados a pensar em uma ação pedagógica cujos conteúdos deveriam estar a serviço de uma educação integral e não em si mesmos.

As normativas que orientam a realizam tais atividades à distância, de alguma forma, se efetuam na base do medo e coerção - o medo de sindicâncias e o de não receber o sustento representado pelo salário. Esse temor amplifica os adoecimentos docentes, pois mesmo que a categoria de professores tenha consciência dos cuidados para com os estudantes, e que ela assume responsabilidades para dar-lhes suporte, nem os sindicatos nem os gestores oferecem amparo suficiente. Outro mecanismo de pressão está no fato dos professores utilizarem seus próprios recursos pessoais para oferecer e realizar educação à distância - o computar, o celular, a rede de internet, o plano de dados, a própria casa. Neste cenário, sem espaço para discussão e para compartilhar decisões, as propostas e ações se desenrolam no plano individual - tanto a elaboração quanto a responsabilização - o que resulta em efeitos e riscos ainda imprevistos.

Há uma parcela docente que vive isto tudo de modo crítico, refletido e com responsabilidade. E claro, uma grande parcela que atua de maneira acrítica e deslumbrada com a tecnologia, encanta-se com o potencial descoberto no aprendizado, mas não olha o horizonte para conferir se permanecerá nele; nem sequer pondera sobre o lugar privilegiado da escola como espaço de encontros. Os efeitos imediatos e vindouros sobre a vida docente é algo que será ainda muito investigado, mas o que se vive e se compartilha hoje não é animador.

Outro terreno fértil para o oferecimento acrítico das atividades remotas é que se agrava, se nutre, o distanciamento que uma parcela da categoria docentes tem em relação aos estudantes periféricos da escola pública: a ação online mantém esses professores longe de crianças e jovens pobres, negros e de suas comunidades perigosas. A distância evita que sintam o cheiro da escola, das ruas empoeiradas e da merenda. É duro e melindroso o tema, mas reconheçamos: há um número considerável de profissionais que prefere a distância das crianças e jovens, amedrontados que vivem pelo desgaste cotidiano da violência escolar, do bullying e do descaso estrutural. Também afetados pela impotência diante das condições adversas de trabalho e estudo, o professor e professora 
$\overline{\text { sofre tudo isso e individualiza a interpretação e as possibilidades - ensimesmados, se }}$ fragilizam mais.

Um risco evidente é que se está também recorrendo, novamente ao "messianismo romântico" da atividade do professor e a negação de sua profissionalidade - é muito comum essa romantização ser divulgada pela mídia televisiva. "Ser professor é ter uma missão nobre". Ora, a missão não "paga o boleto" e não alimenta a família! Por um lado, ele deveria ser um profissional exemplar e capaz de se reinventar em poucos dias para ensinar à distância, por outro, ele não pode deixar de oferecer suporte e apoio emocional aos seus estudantes! Sua vocação é cuidar dos alunos com amor e dedicação. Que dilema: cuidar de si e dos seus sabendo que muito provavelmente, se adoecer seriamente, recorrerá ao depauperado sistema público de saúde. Em que pese seu modo de estar confinado com seus filhos e velhos, precisa ser o bastião da criatividade, da responsabilidade e da resiliência para ensinar aos jovens a superar as dificuldades!

Esse tratamento tem muitos elementos invisíveis, armadilhas: a tecnologia salvadora da educação como serviço; as relações de trabalho postas em outras bases de contrato, de desenvolvimento; as patentes e autorias; o direito de imagem e a proteção de dados. Esses elementos recentes não faziam parte das preocupações da categoria docente, nem dos sindicatos até então e não têm recebido a devida atenção das autoridades educacionais.

A saída apressada por atividades educacionais online impõe uma expectativa exagerada sobre a capacidade de ação das famílias: elas, além de ter que sobreviver ao vírus precisam arquitetar a escola domiciliar ${ }^{5}$. Um espanto. Sofrem as famílias e crianças. Tanto que em uma atividade compartilhada pela internet a criança estaria a declarar para a professora: "É muito difícil ser aluno da minha mãe".

\section{Disputas silenciosas no contexto da pandemia}

Há pouca atenção, mas uma questão em profunda disputa se encontra em franco desenvolvimento nesse contexto da pandemia: a defesa da educação à distância na educação básica.

É um tema de interesse milionário pelas grandes empresas de serviços educacionais e que recebe a complacência do atual governo federal, mas também em muitos gabinetes estaduais. O capital empresarial não vê crise, vê aposta em ganhos futuros, nem que para isso se utilize desse ambiente totalmente novo e desestruturado da 
pandemia para testar as estratégias de implementar o ensino à distância em larga escala. A parcela dos educadores mais críticos dessa modalidade ou tendência não está no poder no âmbito federal, não controla conselhos estaduais nem as deliberações municipais, estando silenciada em muitos estados e municípios. Por outro lado, é a força do mercado educacional privado que alçou ter acesso e controle no campo das decisões e do investimento público - veja-se a origem da atual composição do MEC, dos conselhos de educação. O resultado é que muito da escola pública será revirado e transformado para que assuma atividades à distância como instrumentos de ensino, ou melhor, de reprodução de conteúdos de ensino, nem que para isso tenha que culpabilizar mais ainda a classe docente pelas limitações de suas ações na pandemia. A leitura dessa mudança ainda não está no radar de muitos professores colaboradores voluntariosos, que postam seu trabalho em plataformas online, abertas, sem se perguntarem se deviam ser remunerados, não por seu trabalho, mais pelos produtos que oferecem.

É provável, ainda, que como resultado dessa disputa quanto aos modos de realizar o ensino escolar resulte no acesso dos grandes grupos privados ao orçamento público da educação, motivo de cobiça e não de compromisso social, como fazem parecer.

\section{Concepções e referenciais teóricos: o distanciamento e a negação da práxis}

Equívocos diversos e uma conclusão preliminar: os sistemas educacionais públicos e privado, em que pese os avanços das pesquisas na educação sobre cognição, neurociência, bem como sobre processos formativos abertos, plurais que apontam metodologias pedagógicas singulares para distintos contextos, continuam fixados na aplicação de um currículo ferrenhamente realizável apenas pelo cumprimento de conteúdos consolidados, na leitura de temas históricos e contemporâneos com objetivo de realizar provas num horizonte definido. Agora até mesmo virtuais!

Essa prática educativa com foco nos conteúdos impede que professores, mais livres, capacitados e merecedores da confiança das escolas, possam problematizar esse evento da pandemia para questionar seus estudantes e a si próprio. Afinal, que educação estávamos praticando em nossos encontros presenciais e quais dos conteúdos desenvolvidos, por exemplo no ano passado, servem para orientar a leitura e compreensão desse momento histórico, pandêmico: uma crise sanitária; a ameaça biológica invisível; os desdobramentos econômicos, culturais e emocionais. Talvez até a crença no terraplanismo! Se é detectável algumas decisões de gestão e planejamento descoladas do 
conhecimento e dos referenciais educacionais de modo geral, é preciso buscar também a concepção de educação geográfica que está mobilizando os professores do campo e o tipo de atividade didática que estão produzindo.

Outro desafio enorme: no campo do conhecimento geográfico há um sem número de pesquisas que confirmam uma busca incessante da comunidade geográfica para estabelecer o ensino de geografia em novos parâmetros e referenciais. É um trabalho que recebe esforços acadêmicos por mais de 30 anos e o resultado é um conjunto de propostas pedagógicas que, hoje, dão lugar às vivências dos estudantes; entende-se que a aula se inspira na vida e volta a ela com novos modos de agir e pensar dos alunos. E esta aprendizagem, esse desenvolvimento de um pensamento espacial muda a relação dos sujeitos com seus lugares, com o mundo. É esta visão da contribuição da geografia escolar na formação dos sujeitos que melhor pode contribuir, hoje, para que se problematize o contexto atual, o isolamento, a pandemia e o lugar do ser humano no mundo produzido por ele. Mas também naquilo que não depende dele. A geografia da decoreba, da repetição de informações ou das notícias de revistas semanais sem embasamento conceitual não ajudará muito a fazer educação hoje. Para tanto, não se faz necessário malabarismo teórico, mas simplicidade, compromisso e rigor, como propõe Suertegaray (2017).

Nas aulas de Geografia poderia prevalecer a compreensão da dinâmica global da disseminação do vírus, a trilha do adoecimento e mortes, bem como a relação com a cadeia produtiva e de circulação de bens, mercadorias e pessoas, por exemplo. Igualmente, o significado de viver na metrópole em tempos de mobilidade populacional controlada: que fazer com a vida nas cidades conurbadas e suas articulações imprescindíveis? Como tal conurbação problematiza a condução da crise sanitária, de saúde, nos serviços essenciais e mobilidade via transporte público? Essa relação conteúdo com temas contemporâneos já exploramos em um texto de 2015, quando questionamos a abordagem do conceito de sustentabilidade em relação às práticas espaciais de estudantes e docentes na vida urbana (Santana Filho, 2015).

Outro elemento que deveria estar na ordem do debate educacional é o questionamento para essa perspectiva de que as crianças estejam sendo adestradas desde o ensino fundamental para processos seletivos de acesso às universidades. Crianças e adolescentes cuja educação está moldada para a concorrência, não para que se perguntem sobre os princípios éticos e estéticos que predominam na vida em sociedade e, assim, vislumbrem-se como homens e mulheres mais justos, solidários. O que se vê recentemente é grande atenção à concepções errôneas e crendices (quem não tem ouvido 
falar da terra plana e em movimento antivacinas!), quando a educação escolar deveria produzir alfabetização científica - geográfica em nosso caso - e não a reprodução de declarações de fé no mercado e no sagrado, muito menos no individualismo competitivo. Porém, é possível reconhecer que a luta ferrenha para manutenção de calendário escolar, para reabertura de escolas em tempos de pandemia etc. se baseia numa concepção muito equivocada de educação. Ao menos de uma educação que se ponha a serviço de produzir em nós mais humanidade.

Afinal, que tipo de ser humano uma crise planetária ensina que precisamos formar? Como ficam a infância, as mulheres e seus afazeres na situação de isolamento físico e social? Que educação para lidar com o risco, com o perigo e como ser solidário e ágil numa calamidade? Quais atividades podem ser oportunidade para que crianças e jovens se perguntem por sua a relação com o mundo, com as pessoas e, ao mesmo tempo, lhes ponha em movimento para viver a emergência de uma crise que marcará o resto de suas vidas? Todas essas questões poderiam estar na ordem do dia para a proposição de atividades educativas e menos no cumprimento dos conteúdos dos currículos e dos livros do PNLD ou na manutenção de aulas remotas.

Se algo fica explícito até o momento é que a escola pública, ao menos na metrópole fluminense, está longe de ter preparado crianças, jovens e educadores para o momento de urgência, de cuidado mútuo e empatia.

Essa educação formará um ser humano capaz de conviver com a diferença, o cuidado de si e de outro, do planeta-casa?

A resposta, ao menos hoje, é um desalento. A resistência virá, contudo.

\section{Notas}

1 - Essas posturas motivaram muitas ações junto ao Ministério Público do Estado do Rio de Janeiro, tendo por alvo escolas privadas, prefeituras diversas e o próprio estado.

2 - Recomendação 01/2020 do MPRJ. Ver em:

http://www.mprj.mp.br/documents/20184/540394/recomendao_covid19_educao_distncia_esco las_estaduais.pdf, acessada em 10/04/2020.

3 - Ação Civil Pública MPRJ, ver em:

http://www.mprj.mp.br/documents/20184/540394/petio_inicial_acp_covid_19_verso_final_for matada assinado.pdf, acessado em 20/04/2020.

4 - Idem, pág. 11.

5 - O que contraria a Constituição e a decisão do Supremo Tribunal Federal, contrárias à natureza da home schoolling. 


\section{Referências}

BRASIL. [Constituição (1988)]. Constituição da República Federativa do Brasil: promulgada em 5 de outubro de 1988.

MPRJ, Ministério Público do Estado do Rio de Janeiro, Recomendação 01/2020 do $M P R J$,

Em:

http://www.mprj.mp.br/documents/20184/540394/recomendao_covid19_educao_distn cia_escolas_estaduais.pdf, acessada em 10/04/2020.

MPRJ, Ministério Público do Estado do Rio de Janeiro. Ação Civil Pública MPRJ, Em: http://www.mprj.mp.br/documents/20184/540394/petio_inicial_acp_covid_19_verso_f inal_formatada_assinado.pdf, acessado em 20/04/2020.

SANTANA FILHO, Manoel Martins de. "A invenção da sustentabilidade - o nome, as vivências e as possibilidades de vida como práticas espaciais contemporâneas", In: SACRAMENTO, A.R.; ANTUNES, C. F.; SANTANA FILHO, M.M. (Orgs) Ensino de Geografia: produção do espaço e processos formativos. $1^{\mathrm{a}}$ edição. Rio de Janeiro: Consequência, 2015.

SUERTEGARAY, Dirce Maria Antunes. (Re)Ligar a Geografia: Natureza e Sociedade. Porto Alegre: Compasso Lugar-Cultura, 2017.

TUAN, Yi-Fu. Paisagens do Medo. São Paulo: Editora Unesp, 2005. 